\section{Detergent and Enzyme Treatment of Apoptotic Cells for the Observation of DNA Fragmentation}

BioTechniques 24:558-560 (April 1998)

The uniform degradation of genomic DNA into oligomers of approximately 180-200 bp, or multiples of that, characterizes internucleosomal cleavage of DNA. Such fragmentation is a biochemical hallmark of apoptosis (6). Agarose gel electrophoresis is the most common way to demonstrate the laddering pattern of apoptotic DNA. Traditional purification protocols for the isolation of DNA from apoptotic cells require RNase and proteinase digestion of samples. DNA is then extracted using potentially hazardous solvents such as phenol and chloroform, followed by precipitation. Additional time is needed to dissolve the precipitated DNA into buffer before the sample can be analyzed by agarose gel electrophoresis for the presence of internucleosomal DNA fragmentation. This procedure can take two days. The quantity and quality of DNA recovered from apoptotic cells varies depending on the manipulation of the sample and the protocol used (5). Shearing of DNA during extraction results in the appearance of smears on agarose electrophoretic gels that can obscure the internucleosomal-sized DNA fragments seen in apoptosis. These ambiguous results could easily be misinterpreted as necrosis based on the DNA degradation patterns observed $(1,2)$. In addition, many figures in journals depicting gel electrophoresis of apoptotic DNA lack the complete spectrum of internucleosomal-sized fragments because of the absence of either large or small oligomers, therefore resulting in loss of data $(3,4)$.

We demonstrate that solvent extraction and subsequent precipitation are not required for analysis of DNA fragmentation. Only gentle detergent and enzyme treatment of apoptotic cells at $37^{\circ} \mathrm{C}$ are required to observe DNA fragmentation by agarose gel electrophoresis. Our method provides a rapid test for detection of the smaller apoptotic oligomers produced in a ma- jority of apoptotic cells. It could also be used to analyze large DNA fragments by pulse gel electrophoresis in which genomic DNA is not completely fragmented.

This new procedure uses high-percentage agarose gels to increase resolution for smaller oligomers. This allows us to quickly determine whether a cell undergoes apoptotic internucleosomal DNA fragmentation. With 45 min of DNA preparation and $1 \mathrm{~h}$ of electrophoresis, we are able to discern that DNA fragmentation has occurred in various cell lines. Thus, preparation and electrophoresis time is greatly reduced, and the yield and integrity of the DNA sample are not compromised by extraction and precipitation procedures. In addition, reduced cost of the reagents and limited exposure to hazardous solvents make this protocol a much more attractive alternative to conventional DNA extraction methods.

For demonstration of this method, we induced apoptosis in L929 and WEHI-164 cells with tumor necrosis factor (TNF) and BW5147 cells with dexamethasone. Treatment of L929 and WEHI-164 cells with $1000 \mathrm{U}$ of murine recombinant TNF (Genentech, San Francisco, CA, USA) per milliliter for $18 \mathrm{~h}$ induces apoptosis (1). BW5147, a T-cell lymphoma cell line, also undergoes glucocorticoid-induced apoptosis within several hours of treatment with $10^{-7} \mathrm{M}$ dexamethasone. Treated and untreated cells were collected in 1.5$\mathrm{mL}$ microcentrifuge tubes and washed once with $1 \mathrm{~mL}$ of $0.02 \%$ EDTA in Hanks' balanced salt solution (HBSS) without $\mathrm{Ca}^{2+}$ or $\mathrm{Mg}^{2+}$. The cells were pelleted by centrifugation for $5 \mathrm{~min}$ at $700 \times g$; then $40 \mu \mathrm{L}$ of the TE lysis buffer $(10 \mathrm{mM}$ Tris- $\mathrm{HCl}, 1 \mathrm{mM}$ sodium-EDTA, $\mathrm{pH}$ 7.5) containing $0.25 \%$ Nonidet ${ }^{\circledR}$ P-40 (NP40) or Triton ${ }^{\circledR}$ X100 were added along with $5 \mu \mathrm{L}$ of an RNase A solution (20 mg/mL) (Sigma Chemical; St. Louis, MO, USA). The mixture was suspended by gentle vortex mixing and incubated for $20 \mathrm{~min}$ at $37^{\circ} \mathrm{C}$. Then, $5 \mu \mathrm{L}$ of a proteinase $\mathrm{K}$ solution $(20 \mathrm{mg} / \mathrm{mL})$ (Sigma Chemical) were added to the sample and incubated an additional $20 \mathrm{~min}$ or until the solution cleared. A $6 \times$ loading buffer $(5$ $\mu \mathrm{L}$ of $0.025 \%$ bromophenol blue, $0.025 \%$ xylene cyanol FF, $30 \%$ glyc- erol) was added to $25 \mu \mathrm{L}$ of the sample. The sample was then analyzed by electrophoresis on a $1.8 \%$ agarose minigel in TE buffer (40 mM Trisacetate, $1 \mathrm{mM}$ EDTA, $\mathrm{pH} 8.0$ ) for $1-4 \mathrm{~h}$ at $36 \mathrm{~V}$. Ethidium bromide-stained DNA was visualized by transillumination with UV light (300 nm) and photographed (5).

For fragmentation analysis, the sample preparation time using conventional organic solvent extraction methods required 2 days, compared to $45 \mathrm{~min}$ for the technique described above. The induction of internucleosomal DNA fragmentation in various cell lines used was highly discernible using this technique. Figure 1A shows electrophoresis of DNA isolated from L929 cells untreated and treated with TNF for various times. After $6 \mathrm{~h}$ of exposure to TNF, induction of apoptosis in L929 cells is clearly evident by distinct oligosomal DNA fragments ranging from $2.4 \mathrm{~kb}$ through the final 200-bp fragment (Figure 1A, lane 4). As determined by trypan blue exclusion, $72 \%$ of the L929 cells were still viable after $6 \mathrm{~h}$ of TNF treatment. DNA samples extracted from the same number of

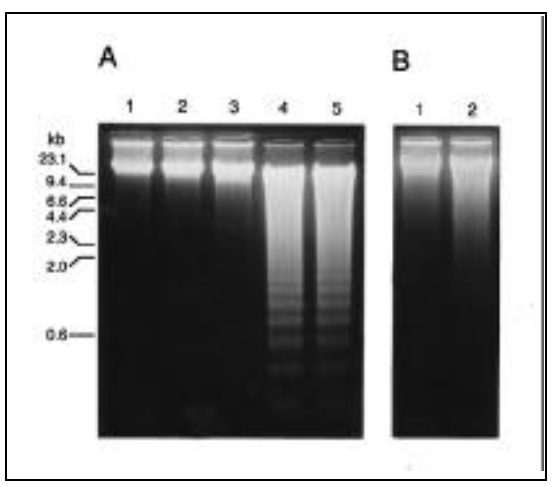

Figure 1. A comparative gel demonstrating differences between proteinase/detergent and phenol/chloroform DNA preparation techniques using TNF-induced apoptotic DNA from L929 cells. (A) DNA isolation by proteinase and detergent treatments from $5 \times 10^{5}$ L929 cells untreated (lane 1) or treated with $1000 \mathrm{U}$ $\mathrm{TNF} / \mathrm{mL}$ for 2, 4, 6 and $24 \mathrm{~h}$ (lanes 2-5) were electrophoresed on a $1.8 \%$ mini agarose gel for 4 h. L929 cells exposed to TNF for 2 and $4 \mathrm{~h}$ were $96 \%$ viable by trypan blue exclusion; however, by 6 and 24 h, viability reduced to $72 \%$ and $9 \%$, respectively. (B) DNA from $5 \times 10^{5}$ L929 cells either untreated (lane 1) or treated with $1000 \mathrm{U}$ $\mathrm{TNF} / \mathrm{mL}$ for $24 \mathrm{~h}$ (lane 2) was isolated by conventional phenol/chloroform extraction methods and electrophoresed on a $1.8 \%$ mini agarose gel for $4 \mathrm{~h}$. 
TNF-treated L929 cells by conventional solvent extraction methods result in degradation of the sample and loss of smaller-sized oligomers (Figure 1B). As a result, the typical oligosomal ladder associated with apoptotic DNA fragmentation is very difficult to discern because of smearing and the absence of the lower portion of the DNA fragmentation ladder. Furthermore, induction of apoptosis and the resultant DNA fragmentation by dexamethasone treatment of BW5147 cells, a T-cell lymphoma, could be detected within 24 $\mathrm{h}$ before any significant loss of cell integrity could be detected by trypan blue exclusion (Figure 2, lane 3). DNA fragmentation in TNF-treated WEHI-164 cells is also highly discernible after electrophoresis for $1 \mathrm{~h}$ on a $1.8 \%$ agarose gel (Figure 2, lane 5). Interestingly, this technique is able to detect WEHI-164 cells going through senescence in culture, presumably by apoptosis, because DNA fragmentation could be detected in untreated samples (Figure 2, lane 4). Because WEHI-164 grows well in culture, we presume only a small proportion of the cells spontaneously undergoes DNA fragmentation. This indicates that the procedure can detect DNA fragmentation in a generally healthy cell population. Our laboratory has also successfully used this technique to isolate and visualize apoptotic DNA from various cell lines treated with campothecin, a topoisomerase II inhibitor and apoptosis inducer (data not shown).

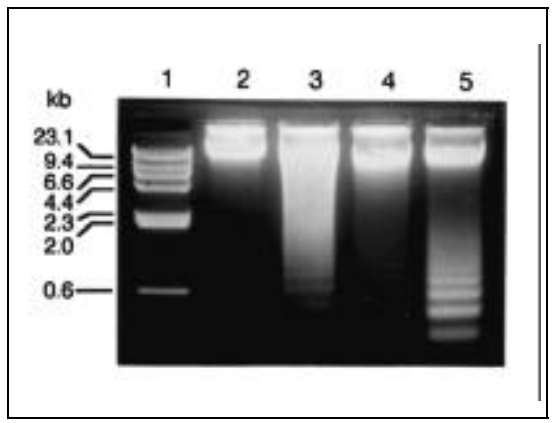

Figure 2. Apoptotic DNA fragmentation induction in a B-cell lymphoma and fibrocarcinoma by glucocorticoid and cytokine treatment. HindIII-digested $\lambda$ DNA (lane 1) and DNA from untreated $5 \times 10^{5}$ BW5147 and WEHI-164 cells, either untreated (lanes 2,4) or treated with $10^{-7} \mathrm{M}$ dexamethasone or $1000 \mathrm{U} \mathrm{TNF} / \mathrm{mL}$, respectively, for $24 \mathrm{~h}$ (lanes 3,5), were electrophoresed on a $1.8 \%$ mini agarose gel for $1 \mathrm{~h}$.
This technique results in sharp 200bp multiples indicative of the activation of endonucleases in the apoptotic processes. Importantly, high-percentage agarose gels allow tight band formation and thus distinct visualization of laddering patterns by smaller apoptotic DNA fragments after as little as one hour of electrophoresis. This protocol simplifies the identification of internucleosomal DNA fragmentation in a variety of apoptotic cells, thus improving the ability to produce rapid and concise results.

\section{REFERENCES}

1.Fady, C., A. Gardner, F. Jacoby, K. Briskin, Y. Tu, I. Schmid and A. Lichtenstein. 1995. Atypical apoptotic cell death induced in L929 targets by exposure to tumor necrosis factor. J. Interferon Cytokine Res. 15:71-80.

2.Gera, J.F., C. Fady, A. Gardner, F.J. Jacoby, K.B. Briskin and A. Lichtenstein. 1993. Inhibition of DNA repair with aphidicolin enhances sensitivity of targets to tumor necrosis factor. J. Immunol. 151:3746-3757.

3.Jarvis, W.D., R.N. Kolesnick, F.A. Fornari, R.S. Traylor, D.A. Gewirtz and S. Grant. 1994. Induction of apoptotic DNA damage and cell death by activation of the sphingomyelin pathway. Proc. Natl. Acad. Sci. USA 91:73-77.

4.Kyprianou, N., R.B. Alexander and J.T. Isaacs. 1991. Activation of programmed cell death by recombinant human tumor necrosis factor plus topoisomerase II-targeted drugs in L929 tumor cells. J. Natl. Cancer Inst. 83:346350 .

5.Sambrook, J., E.F. Fritsch and T. Maniatis. 1989. Molecular Cloning: A Laboratory Manual, 2nd ed. CSH Laboratory Press, Cold Spring Harbor, NY.

6.Wyllie, A.H. 1980. Glucocorticoid-induced thymocytes apoptosis is associated with endogenous endonuclease activation. Nature 284:555-557.

This work was supported by the American Heart Association and the Geist Foundation. Address correspondence to Darren J. Park, Department of Microbiology, University of Hawaii, 2538 The Mall, Snyder Hall 318, Honolulu, HI 96822, USA. Internet:darrenp@hawaii.edu

Received 23 June 1997; accepted 15 December 1997.

Darren J. Park and Paul Q. Patek University of Hawaii Honolulu, HI, USA 